\title{
Rent Burden and Depression Among Mothers: an Analysis of Primary Caregiver Outcomes
}

\author{
Stacy Elliott ${ }^{1}$ (D) $\cdot$ Stacia M. West ${ }^{1} \cdot$ Amy B. Castro $^{2}$
}

Accepted: 25 August 2021 /Published online: 13 September 2021

(c) The Author(s), under exclusive licence to Springer Nature Switzerland AG 2021

\begin{abstract}
Using national longitudinal survey data from the Fragile Families \& Child Wellbeing Study (FFCWS), this study builds on existing knowledge about housing insecurity, female caregivers, and well-being. The study analyzed the relationship between housing cost burdens (HCB) and depression among a sample $(N=399)$ of predominantly (67.6\%) Black non-Hispanic mothers and other female primary caregivers. A generalized estimating equation (GEE) model yielded results that indicate housing cost burden among mothers and other female primary caregivers has a statistically significant association with meeting symptoms of depression and liberal criteria for depression as measured by the CIDI-SF survey instrument. This study contributes to the knowledge base of health outcomes related to housing cost burden by providing a unique analysis of the association of depression and housing cost burden at an unprecedented scale by using data from several consecutive waves of survey responses of a large, multi-city, longitudinal study. The findings hold implications that may inform future policy and research concerning the affordable housing crisis, which disproportionately affects mothers and other female heads of household. Considering the prevalence of housing cost burden in the USA and the disproportionate indications of depression found among housing burdened mothers/female caregivers, the findings of this study may hold implications for housing and health policies that address U.S. communities as diverse as the wide range of communities from which the FFCWS respondents were drawn.
\end{abstract}

Stacy Elliott

jellio32@vols.utk.edu

Stacia M. West

swest11@utk.edu

Amy B. Castro

amycastro@sp2.upenn.edu

1 University of Tennessee, Knoxville, USA

2 University of Pennsylvania, Philadelphia, USA 


\section{Introduction}

Too many Americans experience high housing cost burdens. The most recent US Bureau of Labor figures note that the average American household consistently spent about $33 \%$ of its income on housing costs for the past 4 years, making housing costs the largest annual expenditure for most American consumers (Bureau of Labor Statistics, 2020). Prior to the COVID-19 pandemic, around 37.1 million US households spent over 30\% of their income on housing, meeting the standard definition of housing cost burden. In 2019, over $46 \%$ of all renters experienced cost burdens, and nearly a quarter of all US renting households experienced severe housing cost burdens (Joint Center for Housing Studies, 2020).

The term "housing cost burden" typically references housing costs exceeding $30 \%$ of income (Jewkes \& Delgadillo, 2010; McConnell, 2013). Although housing cost burden is experienced by households at a wide range of income levels in areas with varying housing affordability characteristics, residents or tenants with lower income levels often experience disproportionately higher rates of burden (McConnell, 2013). The most common indices of US housing affordability are the Department of Housing and Urban Development (HUD) Affordability Index for homeowners and renters, the National Low-income Housing Coalition Affordability Index for renters, and the National Association of Realtors Affordability Index for homeowners (Jewkes \& Delgadillo, 2010). Though there is no gold standard for indexing or measuring housing cost burden, traditional housing-cost-to-income ratio measurements typically represent the established norm (Mulliner et al., 2016; Newman \& Holupka, 2015; Nwuba \& Kalu, 2018).

Financial stress caused by the housing cost burden impacts health and well-being (Braubach, 2011; Gibson et al., 2011; Kavanagh et al., 2016; Ortiz \& Johannes, 2018; Shaw, 2004). Physical and psychological health consequences have been linked to issues of housing affordability (Krieger \& Higgins, 2002; Lubell et al., 2007; Mason et al., 2013; Ortiz \& Johannes, 2018; Pollack et al., 2010; Woolf \& Braveman, 2011), and housing cost burden has been identified as one of the greatest barriers to accessing healthcare (Ortiz \& Johannes, 2018). Financial stress caused by the housing cost burden carries disproportionate effects on mothers and female caregivers, including a greater risk of poor health and maternal depressive symptoms (Ortiz \& Johannes, 2018; Sandel et al., 2018). Financial hardships, depressive symptoms, poor health outcomes, increased rates of their children being hospitalized, and higher rates of parenting stress are all endemic among mothers facing eviction (Desmond \& Kimbro, 2015; Ortiz \& Johannes, 2018).

Given the importance of better understanding and addressing issues of the housing cost burden and health outcomes, and the disproportionate impact experienced by female caregivers, this study aims to fill a gap in the literature by analyzing the relationship between housing cost burden and mental health outcomes reported by a large, diverse, and geographically varying sample of rent-burdened primary caregiver mothers. Participants were surveyed multiple times across a span of over 15 years. Using national longitudinal survey data from the Fragile Families \& Child Wellbeing Study (FFCWS), this study builds on existing knowledge about housing insecurity and well-being. The study analyzed the relationship between housing cost burdens $(\mathrm{HCB})$ and depression among a sample $(N=399)$ of predominantly $(67.6 \%)$ Black non-Hispanic mothers and other female primary caregivers. 
As the COVID-19 pandemic places greater strain on those already suffering from income, housing, and wealth disparities implicit in America's market economy, those previously vulnerable to rent burden before the pandemic are at greater peril of experiencing worse housing outcomes (Jones \& Grigsby-Toussaint, 2020; McCargo et al., 2020). Previous research, and emerging research on the ongoing effects of the pandemic on housing cost burdens, suggests we are now living through a critically important time for understanding and addressing the consequences of the current status of housing cost burdens in the USA (Jones \& Grigsby-Toussaint, 2020; McCargo et al., 2020).

\section{Literature Review}

\section{Disproportionate Experiences of Housing Cost Burden}

Familial status, age, race, ethnicity, and geography are associated with disproportionate rates of housing cost burden. In 2018, Harvard's Joint Center for Housing Studies (JCHS) reported that renter households headed by single parents were most likely to be housing cost burdened with over $50 \%$ of such households meeting standard thresholds of housing cost burden; those under 30 and those over 65 were more likely than other age cohorts to experience housing cost burden. In 2020, JCHS found that 20.8 million rental households in the USA are housing cost burdened and that shares of housing cost burden among Black and Hispanic renters were at 54 and $52 \%$, more than $10 \%$ higher than those of White renters. While renters face a unique set of housing stability challenges, US homeowners, and especially homeowners with annual incomes of $\$ 25,000$ or less, also experience high proportion of housing cost burdens as $69 \%$ of this lower income cohort experienced housing cost burdens before the onset of the pandemic. (Joint Center for Housing Studies, 2020).

Other research demonstrates that country of origin and citizenship status of renters and homeowners is predictive of a higher housing cost burden (McConnell, 2013). Racial segregation in housing also appears to be associated with housing cost burden for minoritized groups, households who already experience energy insecurity, or utility cost burden, and low-income immigrant households (Hernández et al., 2016).

\section{Disparate Impacts in Female-Headed Households}

While housing cost burden varies some across different individual attributes and demographic characteristics, female-headed households, and households headed by single-mothers in particular, experience disproportionately higher levels of housing cost burden (Baker et al., 2020; Cook et al., 1994; Pilkauskas \& Michelmore, 2019). Furthermore, these trends occur within a market economy that relies on women performing unpaid care work in the home to sustain the social reproduction that subsidizes the broader economy (Abramovitz, 2012). Leading up to the Great Recession, single women were $32 \%$ more likely to receive subprime mortgages than men, were overrepresented in the pool of subprime mortgages by $29.1 \%$, and women with high 
incomes were $46.4 \%$ more likely to receive subprime mortgages than men with similar incomes (Fishbein \& Woodall, 2006). Women of color were nearly five times as likely to receive subprime mortgages as men of all races in the same income level cohort (Fishbein \& Woodall, 2006). Housing cost burdens are especially threatening to female-headed households as homeownership is a main conduit of asset accumulation for women (Baker, 2018). Research in this area also finds housing unaffordability is significantly associated with maternal stress, indicating that severe housing cost burdens may be a root cause of high levels of stress experienced by mothers (Warren \& Font, 2015). Taken together, the literature indicates that female-headed households in the USA, particularly households headed by mothers or female caregivers, likely experience disproportionate rates of housing cost burden along with other gendered risk factors.

\section{Housing Cost Burden, Housing Affordability, and Health Outcomes Research}

Several studies demonstrate relationships between increased housing costs and poorer health outcomes (Baker et al., 2013; Mason et al., 2013). Meltzer and Schwartz (2015) studied the relationship between rent burden and health outcomes among renters in New York City and found an association between higher rent burden and worse health conditions including a statistically significant association between a $10 \%$ increase in housing cost burden and an increase of 3.5 additional postponements of medical services for financial reasons. When more severe rent burdens were present, there were stronger associations with more severe health conditions and postponement of health care (Meltzer \& Schwartz, 2015). In Philadelphia, the financial strain generated by lack of affordable housing was linked with financial trade-offs that harm health such as postponing or forgoing necessary medical care in lieu of paying for high housing costs (Pollack et al., 2010). A recent study by Clair and Hughes indicated that renters had higher C-reactive protein (CRP) levels, indicating more stress and potential health concerns, than homeowners, and that a number of other housing factors were associated with CRP (2019). Oddly, results indicated that housing cost burden had an association with lower levels of CRP with low-income renters (Clair \& Hughes, 2019). Upon further investigation of this result, Clair and Hughes considered how the sample of low-income renters included both those who rent housing in the private market and those who rent social housing (rental housing that is at least partially subsidized). After accounting for this difference, the researchers found that the effect of social housing rent subsidies on housing cost burden acted as a protective effect for those renters' CRP levels compared to low-income renters who rented through the private housing market without that sort of housing cost assistance.

Prior to the past decade, evidence concerning mental health outcomes associated with housing cost burden remained limited (Bentley et al., 2011), but recent studies demonstrate stress related to housing affordability and housing cost burden is associated with worse scores on measures of mental health and emotional well-being (Baker et al., 2020; Bentley et al., 2011, 2012; Mason et al., 2013). Furthermore, 
men and women appear to experience these effects differently, as men who experienced consecutive years of housing affordability stress averaged significantly worse mental health scores than women in the same cohort (Bentley et al., 2012).

Further demonstrating the relationship between housing cost burden and mental health, longitudinal studies in the UK and Australia have found significant associations between housing costs and stress that results in mental health decline (Bentley et al., 2011; Pevalin et al., 2008). There also seems to be increasing evidence that lower and middle-income renters are more vulnerable to mental health declines related to housing cost burden than home buyers (Mason et al., 2013).

Current literature includes several important studies and reviews on the associations between housing cost burden factors and health outcomes. Potentially critical gaps in the literature emerge from some common limitations found in the aforementioned literature: studies that are geographically bound to one city or metropolitan area, studies that have fairly homogenous samples, studies that do not or cannot pursue questions of possible causality, and a reliance on cross-sectional secondary analysis from multiple different survey instruments. An approach that uses a single integrated design would likely address some of the issues cited by cross-sectional secondary data analyses (Jacobs et al., 2008). A multilevel modeling analysis using a single integrated longitudinal data set might allow a study to further test the association of housing cost burden variables and mental health outcome variables, which is the approach we used in this study.

The purpose of this study is to further the literature on housing cost burden and mental health through answering the following research question: "Is housing cost burden associated with negative mental health outcomes for a nationally representative sample of mothers and female primary caregivers who rent their homes?" We examined health outcomes for a large sample of renters, who were interviewed separately and extensively about several domains of human experience as part of the Fragile Families and Child Wellbeing Study (FFCWS), and possible negative effects that stressors related to housing cost burden may have on this group's health and well-being outcomes.

\section{Methods}

\section{Data}

This analysis used a selected sample of women $(N=399)$ from Fragile Families and Child Wellbeing Study (FFCWS), a joint effort of Princeton University and Columbia University that follows a cohort of families $(N=4,898)$ living in 20 U.S. cities. Working with a third-party survey contractor and several hospitals, the FFCWS research team interviewed unmarried mothers and fathers of newly born children at hospitals in cities selected by the research team between 1998 and 2000 (Reichman et al., 2001). Sampling unmarried mothers resulted in a more ethnically diverse and lower income sample (Reichman et al., 2001). The study of parents and their children spanned over 15 years with six waves of data collection and included repeated measures of housing cost burden and health outcomes. Data from all waves, as well as corresponding codebooks, user 
guides, background materials, and other user resources, are publicly available through the FFCWS website managed by Princeton University (https://fragilefamilies.princeton.edu).

\section{Sample}

The sample for this study consisted of nearly 400 unique FFCWS participants $(N=399)$ who met the following inclusion criteria: mothers or other female-identifying primary caregivers from low-income households who were unmarried at the time of their child's birth and rented their primary residence. The mothers and female-identifying primary caregivers selected for the sample are FFCWS participants who consistently responded to survey items about self-reported symptoms of depression and housing cost burden across all available waves of data collection. The sample was predominantly $(67.7 \%)$ Black, non-Hispanic. This sample of 399 unique participants was narrowed down from the near 5000 total FFCWS participants for several reasons.

The initial baseline interview phase for the FFCWS included biological mothers and fathers. While some survey items and questions were included in follow-up interviews at all six waves of data collection, other items appear less consistently. During some of the more recent waves of data collection, new questions were asked that were not asked in previous waves. In several instances, fathers and mothers were asked similar but not identical questions about their respective experiences. In wave 6 , interview questions were posed only to the "primary caregiver" that previously were addressed to the biological father, mother, or both biological parents.

For these reasons, along with this study's intent of exploring specific research questions pertaining to housing cost burden and health outcomes of FFCWS participants, inclusion and exclusion criteria were determined with the goal of analyzing variables constructed from measures that were consistently, if not uniformly, completed by primary caregiver mothers at every or nearly every wave of data collection. For example, criteria of depression, measured and represented as constructed variables in every wave but the baseline (Wave 1), were included as a health outcome in this analysis. Some measures, such as survey items based on criteria for anxiety disorders, were asked in different and incongruous formats or were completely absent in some waves, and, therefore, were excluded from this analysis of health outcomes.

\section{Measures}

\section{Dependent Variables}

Outcome variables for this analysis were initially chosen based on the literature on the mental health effects associated with housing cost burden. Two of the most salient and consistently reported health outcomes across the six waves of available data are measures of depression and anxiety. By incorporating items from the crossvalidated World Health Organization's Composite International Diagnostic Interview Short-Form (Kessler et al., 1998), or CIDI-SF, FFCWS interviewers captured responses from parents and produced constructed variables in the publicly released dataset. While the CIDI-SF is not without its limitations, predictive validity of the 
CIDI-SF are consistent with the full CIDI. (Kessler et al., 1998). Additional testing of the CIDI-SF indicated good internal consistency, rendering it ideal to use in a study with the size, scope, and purpose of the FFCWS (Gigantestco \& Morosini, 2008; Kessler et al., 1998).

Items to measure Generalized Anxiety Disorder (GAD) were also part of the FFCWS interview protocol. While data were available in waves 2 through 6 for whether a mother met depression criteria, data for responses to GAD were not available for as many consecutive waves. Waves 2, 3, 5, and 6 included variables for meeting criteria of GAD/anxiety, such as "cm3gad_case" for child's mother in Wave 3, while Waves 1 and 4 did not include this sort of variable for mothers. While the literature indicates an association between housing cost burdens and anxiety, a potential variable constructed from GAD item responses was dropped from analysis plans as the available data did not allow for adequate study across multiple years and waves of data collection. Future research of large-scale studies would benefit from data on survey items that consistently measure a sample's reported anxiety across all consecutive waves of data collection. Based on the best available data provided by FFCWS datasets, a determination was made to use a single dichotomous outcome variable for depression, constructed as responses of either "yes" or "no" as to whether or not mothers met the criteria for depression as measured by CIDI-SF items. FFCWS provided two separate constructed dichotomous variables for thresholds for depression, conservative criteria, a higher threshold of more symptoms of depression, and liberal criteria, a lower yet important threshold of multiple symptoms of depression.

In order to run descriptive statistics and statistical models with these variables, FFCWS-constructed variables were recoded using SPSS version 25. The publicly available FFCWS "all waves" dataset included dichotomous variables to indicate whether mothers met ("yes") or did not meet ("no") criteria for depression. These variables existed for both liberal and conservative criteria for depression. The wave 6 variable for "meets liberal criteria of depression" was cp6md_case_lib. This variable, and similar variables on depression criteria from waves two through five, was recoded so that responses of "no" were coded as zero $($ no $=0)$ and "yes" as one (yes $=1)$. The same recoding conventions were used for dichotomous variables related to the health outcome of whether mothers met the criteria for anxiety. These variable transformations were executed to construct the dependent variable "depression." Future research may build on this approach by incorporating a similar process for including variables indicative of anxiety, as this ultimately was not possible for this analysis.

\section{Independent Variable of Interest}

FFCWS survey items regarding housing costs varied across waves in both how and to whom questions were asked. The survey items asking about monthly housing costs varied wave to wave in few important ways: some waves of the survey separately ask both the biological father and biological mother about income and housing costs while other waves only asked one biological parent. For example, baseline/Wave 1 only surveyed the biological father about annual income as the variable "f1k4". Some earlier waves of the survey ask about monthly housing costs without distinguishing if the 
monthly cost was a rental payment or a mortgage payment while later waves include questions that clearly ask respondents to indicate if their monthly housing cost is a rental payment or a mortgage payment (in FF_allwaves_2019 variable “p6j11” represents "rent paid each month" by the primary caregiver for Wave 6/Year 15 whereas previous waves included a variable for "rent paid each month" by the child's mother, such as variable "mdh4" for Wave 2, "m3i4" for Wave 3, "m4i4" for Wave 4, and "m5f4" for Wave 5). Wave 6 addresses all survey questions only to the "primary caregiver," while previous waves of the survey differentiated separate questions for biological father respondents and biological mother respondents.

Although data from survey items that asked biological mothers/female-identifying primary caregivers about monthly renter housing costs are available for five consecutive waves of data collection (Wave 2 through Wave 6), data are not available for monthly mortgage housing costs across the same timeframe of data collection. For these reasons, the construction of a consistent housing cost variable was limited to monthly rent costs and not mortgage costs. Consequently, this narrowed the sample criteria to include renters and exclude homeowners. As the literature indicates housing cost burdens are experienced by both renters and homeowners, further research can expand on this analysis by obtaining longitudinal data that consistently captures monthly mortgage costs.

The rent burden for the sample of mother primary caregivers was calculated by creating monthly income variables and dividing monthly rent amounts by monthly income. To create monthly income variables, annual household income from each wave in the FFCWS dataset was divided by twelve. For example, the variable in the FFCWS data for Wave 5 annual household income, cm5hhinc, was used and divided by twelve to create a Wave 5 monthly income variable, monthincomeW5. With the newly created monthly household income variables, the independent variable of the housing cost burden for respective waves could be calculated by dividing this variable by the corresponding wave's reported monthly rent amount variable. For example, wave 5 housing cost burden, labeled by the new variable rentburdenW5, was calculated by dividing Wave 5 monthly rent amount variable (m5f4) by the Wave 5 monthly income variable using the following syntax computation in SPSS: rentburdenW5 = m5f4/monthincomeW5.

Next, the rent burden was calculated based on prior standards and cut scores. The accepted standard for housing cost burden maintains that monthly housing costs (monthly rent payment amounts in this study's sample) are deemed as burdensome when they exceed $30 \%$ of household income, and severely burdensome when housing costs equal to or exceed $50 \%$ of household income (Schwartz \& Wilson, 2008). Based on these housing cost burdens, rent burden for each wave was recoded in SPSS with cut scores where monthly housing costs less than $31 \%$ of monthly household income were coded as not burdened ( 0 THRU $0.30=0)$, housing costs that were 31 to $49 \%$ of monthly household income were coded as burdened $(0.31$ THRU $0.49=1$ ), and housing costs that were or exceeded $50 \%$ of monthly household income were coded as severely burdened (0.50 THRU HIGHEST $=2)$.

\section{Covariates and Demographics}

Included time-varying covariates in the model were education, number of children under 18 in the household, and status of a partner living in the household with the 
mother. Other demographic control variables that do not vary over time were race and ethnicity. Race and ethnicity of the primary caregiver mothers in this sample were coded as combined variable dataset, in which participants were asked categorical questions of their race, and whether they reported Hispanic ethnicity. This variables was coded as $0=$ white non-Hispanic, $1=$ Black non-Hispanic, $2=$ Hispanic, and $3=$ other.

\section{Data Analysis}

IBM SPSS (25.0) was used to recode variables into categorical variables and to generate descriptive statistics including graphs of residuals. A generalized estimating equation (GEE) model with a fixed effect approach was used to test the research question. GEE (fixed effect) was chosen as the appropriate method for this question because it can accommodate repeated categorical measures where differences within individuals at successive measurement points are assumed to influence the estimation of model parameters. GEE accommodates a two-level data hierarchy in which measurements are nested within individuals, with a dichotomous outcome variable (Heck et al., 2013).

\section{Results}

\section{Results of the GEE Analysis}

Results indicated that rent burden had a statistically significant association with the outcome variable of meeting liberal criteria for depression (Wald's chisquare $=10.586, p=0.005$ ). When controlling for covariates of mother's race, the number of children under age 18 living in the household, mother's education level, and the status of whether or not mother's current partner lives in the household, the results indicated that mothers who experienced rent burden $(O R=1.687, p=0.004)$ or severe rent burden $(O R=1.506, p=0.005)$ were significantly more likely to report liberal criteria of depression than mothers who experienced no rent burden. In other words, the GEE analysis parameter estimates indicated that for every one (1) primary caregiver mother who had no rent burden and met liberal criteria for depression, there were about 1.5 mothers who experienced severe rent burden and met liberal criteria for depression.

Results did not indicate a statistically significant association of within-subject changes in a mother's reported status of meeting liberal depression criteria and experiencing rent burden. Race and ethnicity did not have a significant effect on the association between rent burden and depression. As only 55, or less than $3 \%$, of 1850 initially eligible responses were from mothers who reported the race ethnicity category labeled as "other" for subjects who were not White, nor Black, nor Hispanic, the "other" category was recoded as "missing," changing the number of FFCWS respondents eligible for this study to 1795. Further consideration of sample eligibility based on the availability of responses to survey items concerning symptoms of depression across five consecutive waves of data collection narrowed eligible respondents to a selected sample of $399(N=399)$ for the analysis conducted in 
this study. Over two-thirds (67.6\%) of respondents included in the sample for this analysis were from Black, non-Hispanic mothers or female-identifying primary caregivers. The results of the model did not indicate race as a statistically significant factor in meeting liberal depression criteria.

\section{Mother's Education}

The categorical variable of "mother's education" was collapsed from four categorical response levels to three, with the top two levels of educational attainment combined into one. This was done because so few of the responses over the five waves, only 77 out of 1795 total responses (4.29\%) included in the initial analysis of descriptive statistics, reported the highest possible categorical response of a college degree and/or some graduate school. The education level responses of a college degree and/or some graduate school category were collapsed to be included with the next highest education level responses, "some college" for the analysis of the selected sample of 399 respondents.

Prior to collapsing the categorical variable of mothers' education level, a test of fixed effects indicated that a mother's education level had a significant association with the outcome variable of meeting CIDI-SF liberal criteria of depression $(F=2.736, p=0.042)$. After running the analysis with the new collapsed version of the variable with the narrower selected sample of 399 mothers/female-identifying primary caregivers, mother's education level did not have a statistically significant association with meeting CIDI-SF liberal criteria of depression (Wald's chisquare $=4.254, p=0.119$ ).

\section{Discussion}

Prior to conducting this study, a review of literature on housing cost burden in the USA underscored that housing is too expensive, pay for work is too little, and the stress of managing and surviving this socially and economically unjust predicament can have harmful effects on health, especially for mothers and other female caregiver heads of household. While much of this was evident before, the COVID19 crisis further exposed the deep-seated economic injustices related to housing in the USA. These findings usher greater urgency in the current economic landscape, as this study demonstrates housing cost burden among mothers and other female primary caregivers is associated with the negative health outcome of meeting liberal criteria for depression as measured by the CIDI-SF survey instrument. Importantly, this study leveraged a longitudinal, multi-city dataset, collected over 12 years to lend new insight into health outcomes related to housing cost burden by providing a unique analysis of the association of depression and housing cost burden. The findings of this study hold implications that may inform future policy and research, especially concerning the ongoing affordable housing crisis. Considering the prevalence of housing cost burden in the USA, and the disproportionate indications of depression found among housing cost-burdened mothers and female caregivers, the 
findings of this study may hold implications for housing and health policies that address U.S. communities as diverse as the wide range of communities from which the FFCWS respondents were drawn.

This study's secondary data analysis of housing cost burden also prompts further consideration of why housing research methodology tends to adhere to the same traditional housing-cost-to-income ratio measurements. These measurement methods could and perhaps should be replaced by more comprehensive approaches that are considerate of individual household size, the geographic location of a household, a household's transportation costs, and other household expenses that are typically viewed separately from traditional housing costs (Jewkes \& Delgadillo, 2010). These recommended changes in measures of housing cost burden could also affect future analyses by broadening the sample to allow for comparisons among income strata, household composition, and racial and ethnic identity.

The sample used in this study was comprised entirely of mothers and other female primary caregivers who live in low-income households. Future research on housing cost burden experienced by mothers in low-income households may benefit from considering implications for economic policies that aim to address the historical impact of unpaid reproductive labor disproportionately undertaken by women, exacerbated by multiple phases of inequitable redistribution of unpaid labor falling on women with low incomes (Oksala, 2016). Further research on the effects of the housing cost burden on women should factor in the sorts of health risks related to unpaid women's labor in capitalist societies since their unpaid production and social reproduction work underpins healthcare work and entire health systems (Harman, 2016), while women's own human rights to health are often undermined by these same systems (Chant, 2016).

Further analysis of issues stemming from housing cost burden may require policy work that (1) challenges assumptions about income and work and (2) assesses housing affordability relative to the troubling U.S. trends of rising housing costs and stagnant wages. Future research will likely benefit from approaching similar analyses of generational wealth transfers and income inequities through an intersectional lens that is mindful of the political economy of race and gender.

\section{Limitations}

To assess reported rent burden levels and depression criteria of the sample across multiple points in time, the analysis was limited to cases of mothers who participated in surveys in five consecutive waves of data collection over 12 years; the separate waves of data collection points were not evenly dispersed over that 12-year time span. While the FFCWS complete dataset includes some amount of survey responses from nearly 5000 mother and father caregivers, this study narrowed its focus to responses from 399 unique primary caregiver mothers, making the sample too narrow to approach generalizability and leaving cell sizes too small to fully test both time-varying and fixed covariates. As the survey instruments and interview questions were updated from wave to wave of data collection, it was not possible for this analysis to include any other health or well-being outcomes that were measured 
with the consistency of the CIDI-SF. Due to similar data limitations, the analysis conducted in this study did not make a comparison between mothers and female primary caregivers to fathers and male-identifying primary caregivers. Further housing cost burden research using a large, longitudinal, multi-city dataset may benefit from including this sort of comparison. Future research may better build on the effects of the housing cost burden on health by assessing the potential associations between housing cost burden and a range of mental and physical health metrics that have been measured consistently over time with a sample large enough to approach generalizability.

\section{Implications}

The need to address housing cost burdens is a foremost concern for securing basic human survival. This study operates within the confines of a widely accepted market-based definition of the housing cost burden, although future studies may better explore the inequities of housing cost burdens by challenging the concept of housing itself as a market commodity and redefining it. By connecting the functions of the capitalist housing market back to communities at a neighborhood level, some forms of community practices have found some success in pushing back against the assumptions of the financialization and commodification of housing (Fields, 2015). Future research may possibly build on the analysis of national multi-city longitudinal data by incorporating methods that also zoom in and analyze how housing cost burdens operate at a community or neighborhood level.

The literature review and results of this study, though without a comparison cohort of fathers and male-identifying primary caregivers, underscore the importance of considering the unique challenges of housing cost burdens and related symptoms of depression experienced by mothers and female-identifying primary caregivers. In addition to facing a disproportionate amount of housing cost burdens, social reproduction burdens, caregiver burdens, and other unpaid labor burdens, women also carry the brunt of household management and coordination (CiCiolla \& Luthar, 2019). With this knowledge, any attempt to address housing cost burdens must specifically aim to secure the needs of mothers and other female caregivers.

Overall, housing cost burdens may continue worsening as the full effects of recent federal government policy including the 2019 decision to eliminate Community Development Block Grant (CDBG) funds are unknown. The full impact and lasting effects of the past four years of the U.S. Department of Housing and Urban Development (HUD) slashing its budget by over $\$ 8$ million while simultaneously increasing housing costs for housing program participants is yet to be known (Santiago \& Smith, 2018). These most recent disinvestments in public housing assistance follow decades of institutional interventions such as public-private partnership housing developments coupled with tax break schemes, voucher systems such as Sect. 8 and Housing Choice Voucher Program policies, and other welfare interventions that could be described as neoliberal housing policy strategies (Caplan \& Ricciardelli, 2016). With the current and longstanding issues of housing cost burdens in the USA, the literature and current evidence do not seem to indicate if or how a combination 
of modern capitalist interventions can address the widespread problems of the housing cost burden, and we, perhaps, might do better in solving the problems of housing if housing were framed and perceived as a basic human need related to health outcomes and not considered a capitalist commodity (Aalbers \& Christophers, 2014; Fraser, 2014; Kotz, 2009; Lapavistas, 2009; Rolnik, 2013; Schwartz \& Seabrooke, 2009). Given political realities and limitations of conceiving of housing as a capitalist commodity and not as a basic human right, it may be counterproductive to propose a capitalist or market-based strategy as some sort of solution for inequities and human suffering that seem to be exacerbated by if not solely due to the capitalist commodification of a human need as fundamental as housing.

The USA's continued failure to guarantee every American the right to decent affordable housing is ultimately far more costly than it would be to successfully fulfill the 1949 Housing Act's National Housing Goal of securing a suitable living space for every American family (Hartman, 1998). With that in mind, further research should continue to investigate significant associations between housing cost burden and health issues because what has been described as a national housing affordability crisis could potentially spur on national health crises. In the same vein, as the ongoing COVID-19 pandemic demonstrates, a national health crisis may in turn escalate a national housing affordability crisis. The ongoing national crisis of housing unaffordability dictates the rising rates of housing cost burdens, and, therefore, macro-level solutions for unlocking affordable housing also hold the potential to improve the health and overall well-being outcomes for cost-burdened households. Furthermore, it follows that housing cost burden, and negative health outcomes associated with housing cost burden, may not improve until we see more support for bottom-up efforts to fundamentally alter housing practices to become more community and resident driven, while moving away from market-based solutions that rely on and perpetuate the commodification of housing.

\section{Declarations}

Competing Interests The authors declare no competing interests.

\section{References}

Aalbers, M. B., \& Christophers, B. (2014). Centering housing in political economy. Housing, Theory and Society, 31(4), 373-394. https://doi.org/10.1080/14036096.2014.947082

Abramovitz, M. (2012, February). The feminization of austerity. In New Labor Forum Sage CA: Los Angeles, CA: SAGE Publications, 21(1), 30-39. https://doi.org/10.4179/NLF.211.0000006

Baker, A. C. (2018). Financialisation, home equity, and social reproduction: Relational pathways of risk. Critical Housing Analysis, 5(2), 27.

Baker, E., Bentley, R., \& Mason, K. (2013). The mental health effects of housing tenure: Causal or compositional? Urban Studies, 50(2), 426-442. https://doi.org/10.1177/0042098012446992

Baker, E., Pham, N. T. A., Daniel, L., \& Bentley, R. (2020). New evidence on mental health and housing affordability in cities: A quantile regression approach. Cities, 96, 102455. https://doi.org/10. 1016/j.cities.2019.102455 
Bentley, R., Baker, E., \& Mason, K. (2012). Cumulative exposure to poor housing affordability and its association with mental health in men and women. Journal of Epidemiology and Community Health, 66(9), 761-766. https://doi.org/10.1136/jech-2011-200291

Bentley, R., Baker, E., Mason, K., Subramanian, S. V., \& Kavanagh, A. M. (2011). Association between housing affordability and mental health: A longitudinal analysis of a nationally representative household survey in Australia. American Journal of Epidemiology, 174(7), 753-760. https://doi.org/10.1093/aje/kwr161

Braubach, M. (2011). Key challenges of housing and health from WHO perspective. International Journal of Public Health, 56(6), 579-580. https://doi.org/10.1007/s00038-011-0296-y

Bureau of Labor Statistics. (2020). Consumer expenditures 2019. Retrieved from https://www.bls.gov/ opub/reports/consumer-expenditures/2019/home.htm

Caplan, M. A., \& Ricciardelli, L. (2016). Institutionalizing neoliberalism: 21st-century capitalism, market sprawl, and social policy in the United States. Poverty \& Public Policy, 8(1), 20-38. https://doi.org/10.1002/pop4.128

Chant, S. (2016). Women, girls and world poverty: Empowerment, equality or essentialism? International Development Planning Review, 38(1), 1-24. https://doi.org/10.3828/idpr.2016.1

Ciciolla, L., \& Luthar, S. S. (2019). Invisible household labor and ramifications for adjustment: Mothers as captains of households. Sex Roles, 81(7), 467-486. https://doi.org/10.1007/ s11199-018-1001-X

Clair, A., \& Hughes, A. (2019). Housing and health: New evidence using biomarker data. Journal of Epidemiology and Community Health, 73(3), 256-262. https://doi.org/10.1136/jech-2018-211431

Cook, C. C., Bruin, M. J., \& Winter, M. (1994). Housing cost burden among female heads of housing. Housing and Society, 21(2), 16-31. https://doi.org/10.1080/08882746.1994.11430190

Desmond, M., \& Kimbro, R. T. (2015). Eviction's fallout: Housing, hardship, and health. Social Forces, 94(1), 295-324. https://doi.org/10.1093/sf/sov044

Fields, D. (2015). Contesting the financialization of urban space: Community organizations and the struggle to preserve affordable rental housing in New York City. Journal of Urban Affairs, 37(2), 144-165. https://doi.org/10.1111/juaf.12098

Fishbein, A. J., \& Woodall, P. (2006). Women are prime targets for subprime lending: Women are disproportionately represented in high-cost mortgage market. Report, Consumer Federation of America, Washington, DC.

Fraser, N. (2014). Can society be commodities all the way down? Post-Polanyian reflections on capitalist crisis. Economy and Society, 43(4), 541-558. https://doi.org/10.1515/9780823270941-009

Gibson, M., Petticrew, M., Bambra, C., Sowden, A. J., Wright, K. E., \& Whitehead, M. (2011). Housing and health inequalities: A synthesis of systematic reviews of interventions aimed at different pathways linking housing and health. Health \& Place, 17(1), 175-184. https://doi.org/10.1016/j.healthplace. 2010.09.011

Gigantesco, A., \& Morosini, P. (2008). Development, reliability and factor analysis of a self-administered questionnaire which originates from the World Health Organization's Composite International Diagnostic Interview-Short Form (CIDI-SF) for assessing mental disorders. Clinical Practice and Epidemiology in Mental Health, 4(1), 1-10. https://doi.org/10.1186/1745-0179-4-8

Harman, S. (2016). Ebola, gender and conspicuously invisible women in global health governance. Third World Quarterly, 37(3), 524-541. https://doi.org/10.1080/01436597.2015.1108827

Hartman, C. (1998). The case for a right to housing. Housing Policy Debate, 9(2), 223-246. https://doi. org/10.1080/10511482.1998.9521292

Heck, R. H., Thomas, S. L., \& Tabata, L. N. (2013). Multilevel and longitudinal modeling with IBM SPSS. Routledge. https://doi.org/10.4324/9780203701249

Hernández, D., Jiang, Y., Carrión, D., Phillips, D., \& Aratani, Y. (2016). Housing hardship and energy insecurity among native-born and immigrant low-income families with children in the United States. Journal of Children and Poverty, 22(2), 77-92. https://doi.org/10.1080/10796126.2016.1148672

Jacobs, D. E., Wilson, J., Dixon, S. L., Smith, J., \& Evens, A. (2008). The relationship of housing and population health: A 30-year retrospective analysis. Environmental Health Perspectives, 117(4), 597-604. https://doi.org/10.1289/ehp.0800086

Jewkes, M., \& Delgadillo, L. (2010). Weaknesses of housing affordability indices used by practitioners. Journal of Financial Counseling and Planning, 21(1). https://doi.org/10.1136/jech-2019-212286

Joint Center for Housing Studies of Harvard University. (2020). The state of the nation's housing 2020. Retrieved from https://www.jchs.harvard.edu/sites/default/files/reports/files/Harvard_JCHS_The_ State_of_the_Nations_Housing_2020_Report_Revised_120720.pdf 
Jones, A., \& Grigsby-Toussaint, D. S. (2020). Housing stability and the residential context of the COVID19 pandemic. Cities \& Health, 1-3.

Kavanagh, A. M., Aitken, Z., Baker, E., LaMontagne, A. D., Milner, A., \& Bentley, R. (2016). Housing tenure and affordability and mental health following disability acquisition in adulthood. Social Science \& Medicine, 151, 225-232. https://doi.org/10.1016/j.socscimed.2016.01.010

Kessler, R. C., Andrews, G., Mroczek, D., Ustun, B., \& Wittchen, H. U. (1998). The World Health Organization composite international diagnostic interview short-form (CIDI-SF). International Journal of Methods in Psychiatric Research, 7(4), 171-185.

Kotz, D. M. (2009). The financial and economic crisis of 2008: A systemic crisis of neoliberal capitalism. Review of Radical Political Economics, 41(3), 305-317. https://doi.org/10.1177/0486613409335093

Krieger, J., \& Higgins, D. L. (2002). Housing and health: time again for public health action. American Journal of Public Health, 92(5), 758-768. https://doi.org/10.2105/AJPH.92.5.758

Lapavistas, C. (2009). Financialised capitalism: Crisis and financial expropriation. Historical materialism, 17(2), 114-148. https://brill.com/view/journals/hima/17/2/article-p114_6.xml

Lubell, J., Crain, R., \& Cohen, R. (2007). Framing the issues - the positive impacts of affordable housing on health. Center for Housing Policy, 34, 1-34. http://citeseerx.ist.psu.edu/viewdoc/download?doi= 10.1.1.370.4585\&rep=rep1\&type $=$ pdf

Mason, K. E., Baker, E., Blakely, T., \& Bentley, R. J. (2013). Housing affordability and mental health: Does the relationship differ for renters and home purchasers? Social Science \& Medicine, 94, 91-97. https://doi.org/10.1016/j.socscimed.2013.06.023

McCargo, A., Choi, J. H., \& Walsh, J. (2020). A state framework for delivering targeted housing assistance to people and places hit hardest by COVID-19. Washington, DC: Urban Institute2020), https://www. urban.org/research/publication/state-framework-delivering-targeted-housing-assistance-peopleandplaces-hit-hardest-covid-19

McConnell, E. D. (2013). Who has housing affordability problems? Disparities in housing cost burden by race, nativity, and legal status in Los Angeles. Race and Social Problems, 5(3), 173-190. https://doi. org/10.1007/s 12552-013-9086-X

Meltzer, R., \& Schwartz, A. (2015). Housing affordability and health: Evidence from New York City. Housing Policy Debate, 26(1), 1-25. https://doi.org/10.1080/10511482.2015.1020321

Mulliner, E., Malys, N., \& Maliene, V. (2016). Comparative analysis of MCDM methods for the assessment of sustainable housing affordability. Omega, 59, 146-156. https://doi.org/10.1016/j.omega. 2015.05.013

Newman, S. J., \& Holupka, C. S. (2015). Housing affordability and child well-being. Housing Policy Debate, 25(1), 116-151. https://doi.org/10.1080/10511482.2014.899261

Nwuba, C. C., \& Kalu, I. U. (2018). Measuring housing affordability: The two approaches. ATBU Journal of Environmental Technology, 11(1), 127-143. Retrieved from: https://www.ajol.info/index.php/ atbu/article/view/177577/166927

Oksala, J. (2016). Affective labor and feminist politics. Signs: Journal of Women in Culture and Society, 41(2), 281-303. https://doi.org/10.1086/682920

Ortiz, S., \& Johannes, B. (2018). Building the case for housing policy: Understanding public beliefs about housing affordability as a key social determinant of health. SSM -Population Health, 6, 63-71. https://doi.org/10.1016/j.ssmph.2018.08.008

Pevalin, D., Taylor, M., \& Todd, J. (2008). The dynamics of unhealthy housing in the UK: A panel data analysis. Housing Studies, 23(5), 679-695. https://doi.org/10.1080/02673030802253848

Pilkauskas, N., \& Michelmore, K. (2019). The effect of the earned income tax credit on housing and living arrangements. Demography, 56(4), 1303-1326. https://doi.org/10.1007/s13524-019-00791-5

Pollack, C. E., Griffin, B. A., \& Lynch, J. (2010). Housing affordability and health among homeowners and renters. American Journal of Preventive Medicine, 39(6), 515-521. https://doi.org/10.1016/j. amepre.2010.08.002

Reichman, N. E., Teitler, J. O., Garfinkel, I., \& McLanahan, S. S. (2001). Fragile families: Sample and design. Children and Youth Services Review, 23(4-5), 303-326. https://doi.org/10.1016/S01907409(01)00141-4

Rolnik, R. (2013). Late neoliberalism: The financialization of homeownership and housing rights. International Journal of Urban and Regional Research, 37(3), 1058-1066. https://doi.org/10.1111/14682427.12062

Sandel, M., Sheward, R., de Cuba, S.E., Coleman, S.M., Frank, D.A., Chilton, M., Black, M., Heeren, T., Pasquariello, J., Casey, P., \& Ochoa, E. (2018). Unstable housing and caregiver and child health in renter families. Pediatrics, 141(2). 
Santiago, F. T. E. A. M., \& Smith, R. J. (2018). Housing and community development: Divergent responses to austerity politics. Journal of Community Practice, 26(3), 253-256. https://doi.org/10. 1080/10705422.2018.1490242

Schwartz, H. M., \& Seabrooke, L. (2009). Varieties of residential capitalism in the international political economy: Old welfare states and the new politics of housing. In The politics of housing booms and busts (pp. 1-27). Palgrave Macmillan, London. https://doi.org/10.1057/9780230280441_1

Schwartz, M., \& Wilson, E. (2008). Why the 30 percent of income standard for housing affordability. https://www.census.gov/housing/census/publications/who-can-afford.pdf

Shaw, M. (2004). Housing and public health. Annu. Rev. Public Health, 25, 397-418. https://doi.org/10. 1146/annurev.publhealth.25.101802.123036

Warren, E. J., \& Font, S. A. (2015). Housing insecurity, maternal stress, and child maltreatment: An application of the family stress model. Social Service Review, 89(1), 9-39. https://doi.org/10.1086/ 680043

Woolf, S. H., \& Braveman, P. (2011). Where health disparities begin: The role of social and economic determinants - and why current policies may make matters worse. Health Affairs, 30(10), 18521859. https://doi.org/10.1377/hlthaff.2011.0685

Publisher's Note Springer Nature remains neutral with regard to jurisdictional claims in published maps and institutional affiliations. 